\title{
Risk factors for violence among long-term psychiatric in-patients: a comparison between violent and non-violent patients
}

\author{
C Krüger, D Rosema \\ Department of Psychiatry, University of Pretoria and Weskoppies Hospital, Pretoria, South Africa
}

\begin{abstract}
Objective: The problem of the prediction of violence in psychiatric patients has led to a proliferation of research over the last decade. This study focuses on enduring patient related risk factors of violence, and investigates which long-term patients in Weskoppies Hospital (a specialist psychiatric hospital) are the most likely to commit violent acts. Method: Nursing statistics on violent incidents and other security breaches were collected for 262 long-term in-patients over a six month period (April September 2007). The 41 patients who committed violent acts were compared to the 221 non-violent patients in terms of demographic and clinical variables, using two-way tables and Chi-Square or Fisher's Exact Tests. Results: The prevalence of violence among the long-term patients was 16\%. Fighting among patients was the most common form of violence (58\%). The most significant risk factors of violence among the long-term patients are: A diagnosis of mental retardation; first hospital admission before the age of 40 years; total hospital stay > 12 years; current accommodation in a closed ward; habitual verbal aggression; absence of disorganised behaviour; and being clinically evaluated as unsuitable for community placement. Conclusion: The findings will help to identify those long-term patients most at risk of violence. The subgroup of patients with mental retardation is responsible for a disproportionately large number of violent acts in the hospital. The risk lies not so much in their psychiatric symptoms, but more in their cognitive ability, coping skills and inappropriate admission circumstances. Efforts should be directed - at a provincial level - towards their community placement.
\end{abstract}

Key words: Violence; Risk factors; Inpatients; Mental disorders; South Africa

Received: 29-07-2009

Accepted: $30-11-2009$

\section{Introduction}

The prediction of violence in psychiatric patient populations remains one of the most challenging aspects of working with psychiatric patients. The focus of this article is on enduring patientrelated risk factors of violence in a long-term psychiatric in-patient setting, as opposed to the prediction of imminent violence in individual patients. ${ }^{1,2}$ Moreover, the roles of nursing staff factors such as training and work experience, as well as environmental factors such as patient/nurse ratio and crowding in wards fall outside of the scope of this article. . $^{3-10}$

Previous research has linked aggressive behaviour to certain

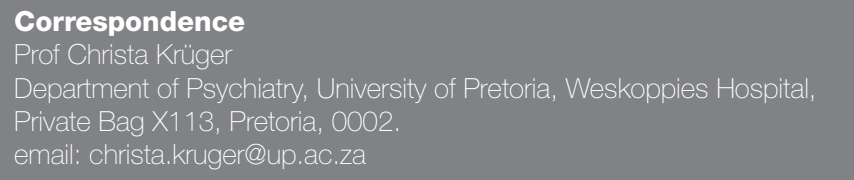

genetic conditions, impaired socio-emotional information processing, demographic variables such as gender and age, and clinical variables such as diagnosis, the presence of mood symptoms, and substance abuse. These will be considered in turn below.

Specific genetic conditions that are associated with aggressive behaviour include the fragile X syndrome (particularly where additionally the high-transcribing long 5-HTTLPR serotonin transporter genotype is involved) and an X-linked mental retardation syndrome resulting from mutations in the Cullin 4B (CUL4B) gene.11,12 A balanced chromosomal translocation involving chromosomes $\mathrm{X}$ and 18, and disrupting the collybistin gene (ARHGEF9) has also been found in a patient with, mental retardation and aggression..$^{13}$ In addition, Karl \& Herzog reviewed the behavioural profile of neuropeptide $\mathrm{Y}$, in relation to aggression. ${ }^{14}$

An association between aggression and inherent cognitive defects - such as impaired social information processing, socio- 
emotional understanding and social and problem-solving skills has been demonstrated in patients with mental retardation and schizophrenia. Inaccuracy in correctly identifying interpersonal intent, a tendency wrongly to attribute hostile intent to others as well as a poorer ability to assess the intensity of emotion has also been demonstrated. ${ }^{15-20}$

Gender as a risk factor for violence has yielded contradictory findings. Numerous studies and meta-analyses have found a significantly higher risk of violence among male psychiatric patients. ${ }^{21-31}$ On the other hand, some studies have demonstrated an increased risk of aggression in female psychiatric patients. ${ }^{32-38}$

In interpreting the contradictory gender-related findings, researchers argue that the greater risk for violence associated with male gender in the general population does not hold true to the same degree in the mentally ill population: The presence of schizophrenia appears to increase women's risk of violence to a greater extent than it does for men's risk, but not to the extent that women with schizophrenia are consistently found to be more violent than men with schizophrenia. 29,39 On the other hand, the predictors of violence depend on the setting: whereas clinical and psychopathological variables may predict violence in institutional settings, demographic and historical variables are better predictors in community settings and in clinical samples consisting of only high-risk patients., ${ }^{9,40}$ External factors are also blamed, e.g., the era of managed health care that changed the profile of admitted patients, or a societal admission bias that causes aggressive women to be admitted sooner than aggressive men. ${ }^{35,38}$

The role of age in predicting violence among psychiatric patients has been examined in various populations, in mentally retarded, forensic and general psychiatry patients. Despite shortcomings such as a lack of a control group in some of these studies, the results are consistent - younger age is associated with more violent behaviour. 3,4,22,23,27,29,31-33,40-47

The complex influence of diagnosis on psychiatric patients' risk of violence has emerged from a variety of studies in different contexts. First, a diagnosis of schizophrenia (and other severe, enduring psychotic disorders) has been demonstrated unequivocally to increase a person's risk of violence in comparison to the general population. $4,6,9,22,23,29,30,32,33,48-55$ The risk of violence is also higher when the psychopathology is more severe, e.g., when more severe positive symptoms of psychosis are present. 4,7,9,32,33,48,53,56,57 Some studies suggest that the effect of a diagnosis of schizophrenia on the risk of violence is only really significant when it is amplified by additional factors such as comorbid/premorbid antisocial conduct or antisocial personality traits. $33,48,49,53,56-59$ Similarly, comorbid substance abuse/dependence dramatically increases the risk of violence in patients with schizophrenia. 1,4,21,23,29,32,33,44,49,56,57,59,60

Another factor that appears to elevate the risk of violence in patients with schizophrenia is the presence of neurological damage, e.g., ventricular enlargement, parieto-occipital atrophy, asymmetrical temporo-parietal gyri, reduced grey matter volume in neural circuits involved in verbal working memory, as well as temporal EEG abnormalities. ${ }^{32,41,46,61-63}$ However, a diagnosis of epilepsy itself has not been proven to increase the risk of violence. ${ }^{41,63}$

Patients with mental retardation have also been demonstrated beyond doubt to commit more violent acts than other members of the general population. 3,8,36,38,61,64,65 Moreover, the presence of a comorbid personality disorder - especially antisocial, but also dependent personality disorder - increases the risk of violence in patients with mental retardation, as it does for patients with schizophrenia. 37,66-69 Similarly, comorbid substance abuse increases the risk of violence in patients with mental retardation. ${ }^{70}$ Furthermore, violent mentally retarded adults have been shown to have larger brain ventricles than their non-violent counterparts, as well as a higher frequency of abnormal EEGs, yet no increased prevalence of seizure disorders (as for schizophrenia). 27,47,71,72

In addition to schizophrenia and mental retardation (with or without comorbidity), the personality disorders as independent primary diagnoses - in particular antisocial and other cluster B personality disorders - are associated with violent behaviour.9,23,33,48-51,57,59,67,73 A primary diagnosis of substance abuse/dependence has also been identified as a strong predictor of violence in psychiatric patients generally., 42,38 Furthermore, mood symptoms, especially irritability, and self-harm have been linked to an increased risk of violence. $2,10,25,27,30,44,50,65,66,74-76$

Regardless of diagnosis, violence in psychiatric patients has remained associated with long-stay hospital admissions. ${ }^{77}$ But even more importantly, the most consistent finding concerning the prediction of violence in the psychiatric context has been that past violence predicts future violence. 1,9,21,23,29,30,53,59,76

Various methodological issues have hampered research progress to clarify enduring patient-related risk factors of violence. First, the use of different definitions of aggressive behaviour and the inclusion of different sets of aggressive or challenging behaviours make it difficult to compare the results of studies. ${ }^{24,78}$ Second, the identification of participants, and assessment of aggression and patient characteristics differ between studies. ${ }^{24,30}$ For example, whereas incident reports might underestimate the prevalence of violence, interview reports lose accuracy by relying on participants' memory. 27,32 Moreover, some studies used no control group. ${ }^{37,66}$ Furthermore, retrospective or cross-sectional versus prospective studies may yield different results. 1,21,36 The setting of a study (community versus in-patient) may also affect the findings, e.g., the prevalence of violence has been found to be low in a university hospital setting. ${ }^{30}$ On the up-side, some epidemiological studies have creatively integrated various databases, such as national hospital admission/discharge records with national forensic conviction registers. ${ }^{21,36}$

The aim of this study was to develop a profile of those longterm psychiatric in-patients at Weskoppies Hospital, Pretoria who are most at risk of committing violent acts. It was hoped that the findings would aid in the clinical management of the long-term patients and in institutional decisions about the services offered to psychiatric patients at Weskoppies Hospital.

Although under the new South African Mental Health Care Act (Act No. 17 of 2002) psychiatric patients are referred to as 'mental health care users', we use the term 'patients' here in the interests of communicating effectively in an international forum. ${ }^{79} \mathrm{Also}$, we use the DSM-IV term 'mental retardation' instead of 'intellectual disability' or 'developmental disability'. 80

\section{Method}

\section{Setting}

Weskoppies Hospital in Pretoria is a 1067-bed specialist psychiatric hospital that renders in- as well as out-patient psychiatric services to a large geographical area, including forensic and child/adolescent-psychiatric services. In accordance with the new South African Mental Health Care Act and the international trend towards de-institutionalisation, the proportion of 
long-term patients in Weskoppies Hospital has also been decreasing progressively, as increasing numbers of long-term patients have been placed in community care. ${ }^{79}$

\section{Design}

This was a quantitative, cross-sectional descriptive study combining clinical file data and routine nursing statistics relating to security breach incidents committed by the long-term in-patients in Weskoppies Hospital. 'Security breach' is a nursing term for any incident that compromises the safety and security of hospital personnel, mental health care users or property which may result in losses for the department. Within the security breaches, violence was defined as assault (on fellow patients or staff), fighting among patients and damage to property.

The primary research question was: Which long-term psychiatric in-patients are the most likely to commit violent acts? More specifically: Are violent long-term psychiatric in-patients different from non-violent long-term psychiatric in-patients with respect to demographic variables, clinical characteristics, or habitual behavioural problems? Regarding the latter, the question is asked whether certain habitual behavioural problems (even non-violent behavioural problems) indicate an increased risk for future violence?

\section{Subjects}

Study subjects included all 262 long-term psychiatric in-patients in Weskoppies Hospital between 1 April and 30 September 2007. Data was collected from ten wards: four open male wards, one semi-closed male ward, one closed male ward, three open female wards and one closed female ward.

\section{Outcome measures}

Nursing statistics of all security breach incidents committed by long-term in-patients were routinely collected during the study period. For each incident, the identifying details of the patient, the ward in which the patient was accommodated at the time of the security breach and the nature of the incident were recorded. Apart from the incidents defined as violent (i.e., fighting among patients, damage to property and assault on fellow patients or staff), data was also recorded on other security breach incidents, including possession of prohibited substances, theft, suicide attempts, arson, burglary, rape/sodomy and drug trafficking of illicit drugs or medication.

Demographic information was recorded from the clinical files: age, gender, level of education, original municipal district, number of admissions, age at first admission, total duration of hospital stay, current ward, involvement by relatives or friends, where they live, and the frequency of their visits. The clinical variables included the current DSM-IV diagnoses, level of functioning and insight, severity of psychopathology, symptom stability, treatment resistance, comorbid general medical conditions, reasons for readmissions, clinical evaluation of suitability for community placement, and the presence/absence of a series of habitual behavioural problems.

\section{Data management and statistical analysis}

The data on all security breach incidents were transferred onto study specific data sheets approved by a statistician from the Department of Statistics, University of Pretoria. The security breach data were linked to individual patients and integrated with their demographic and clinical data. The integrated data set accommodated for the fact that some of the patients had committed multiple offenses of different types.

The relationship between violent incidents on the one hand, and demographic and clinical characteristics on the other, was analysed statistically by comparing the patients who had committed violent acts with the patients who had not committed any violent act during the study period, in terms of the demographic and clinical variables. For these comparisons, twoway tables and Chi-Square or Fisher's Exact Tests were used. Cases with missing data were excluded from analyses. The analyses were conducted by the Department of Statistics, University of Pretoria.

\section{Ethical considerations}

This study received ethics approval from the Research Ethics Committee of the Faculty of Health Sciences, University of Pretoria. A waiver of written informed consent was granted for this study that was exclusively records-based. Written consent was obtained from the Chief Executive Officer of Weskoppies Hospital to access clinical and hospital records. Patient confidentiality was ensured by using unique subject numbers and codes on study specific documentation.

\section{Results}

Figure 1 describes the composition of the study population. Fortyone of a total of 262 long-term psychiatric in-patients (16\%) committed one or more violent acts during the six months study period. These 41 violent patients formed the majority (91\%) of the 45 patients who committed any type of security breach - violent or non-violent (Figure 1). Of the 41 patients who committed violent acts, 28 (68\%) did so only once (Figure 1). The most common form of violence was fighting, at 58\% (Table I). Table II summarises the demographic characteristics of the study population.

When the 41 patients who committed violent acts were

Figure 1: Prevalence of violent acts in study population.

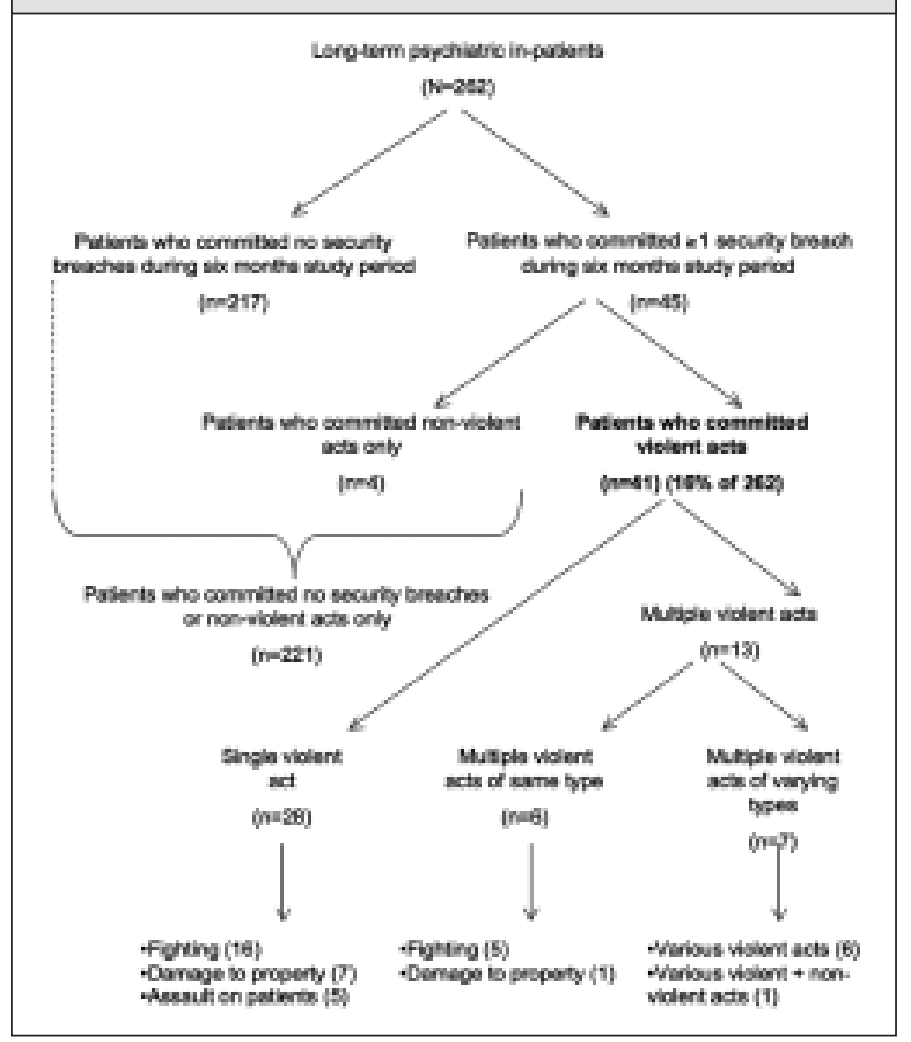


compared to the other 221 patients who committed no security breaches or non-violent acts only, in terms of demographic and clinical variables, a certain profile of statistically significant differences emerged (Table III): The violent patients were more

Figure 2: Proportions of patients in terms of age at first hospital admission who committed violent acts during the six months period.

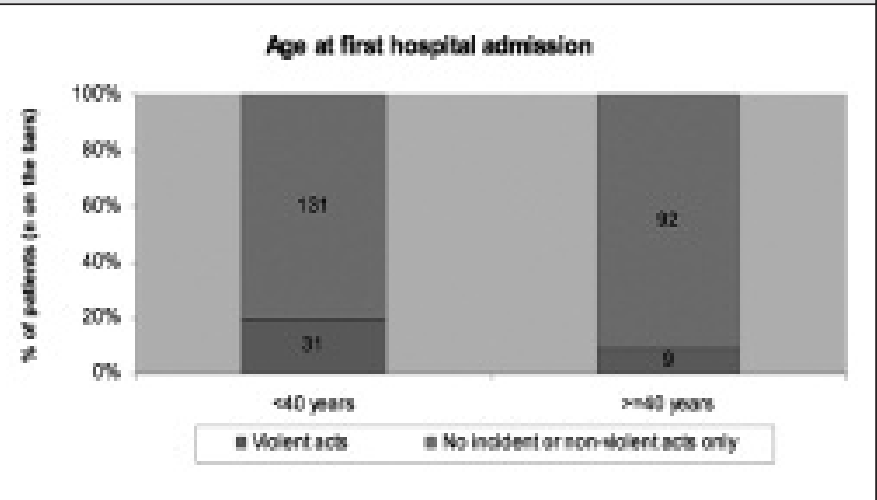

often accommodated in closed wards than the non-violent patients $(p<0.0001)$, more often had their first hospital admission before the age of 40 years $(p=0.0247$ ) (Figure 2$)$, and more often had a hospital stay of longer than 12 years $(\mathrm{p}=0.0258)$ (Figure 3).

Figure 3: Proportions of patients in terms of total duration of hospital stay who committed violent acts during the six months period.

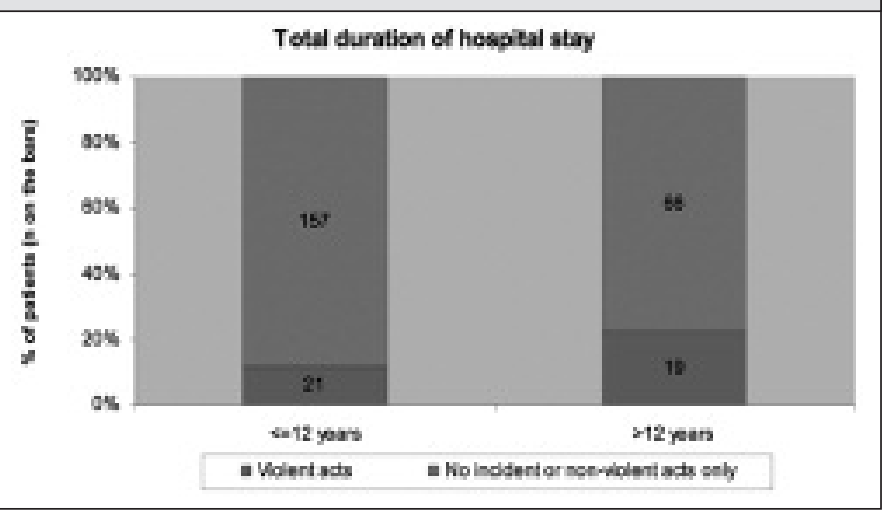

Table I: Types of security breaches committed by $\mathbf{4 5}$ patients during the six months study period

\begin{tabular}{|l|l|l|}
\hline Type of security breach & No of patients & $\%$ of 45 patients * \\
\hline Fighting among patients & & $58 \%$ \\
Damage to hospital property & 26 & $27 \%$ \\
Assault on patients & 12 & $20 \%$ \\
Assault on staff & 9 & $7 \%$ \\
Possession of prohibited substances & 3 & $7 \%$ \\
Theft & 3 & $4 \%$ \\
Suicide attempt & 2 & 0 \\
Arson & 1 & 0 \\
Burglary & 0 & 0 \\
Rape / sodomy & 0 & 0 \\
Drug trafficking - illicit drugs & 0 & 0 \\
Drug trafficking - medication & 0 & 0 \\
\hline * The percentages do not add up to 100\% since some of the patients committed multiple acts of different types. & \\
\hline
\end{tabular}

\section{Table II: Demographic characteristics of study population}

Present age, age at first hospital admission, and total duration of hospital stay:

\begin{tabular}{|c|c|c|c|c|}
\hline & $N$ & Variable & Mean (years) & Std Dev \\
\hline All long-term in-patients & 262 & $\begin{array}{l}\text { Present age } \\
\text { Age at first hospital admission } \\
\text { Duration of hospital stay }\end{array}$ & $\begin{array}{l}49.64 \\
36.73 \\
12.76\end{array}$ & $\begin{array}{l}13.52 \\
13.26 \\
9.48\end{array}$ \\
\hline Patients who committed violent acts & 41 & $\begin{array}{l}\text { Present age } \\
\text { Age at first hospital admission } \\
\text { Duration of hospital stay }\end{array}$ & $\begin{array}{l}48.18 \\
34.31 \\
13.60\end{array}$ & $\begin{array}{l}14.85 \\
13.70 \\
9.20\end{array}$ \\
\hline $\begin{array}{l}\text { Patients who committed no security breaches } \\
\text { or non-violent acts only }\end{array}$ & 221 & $\begin{array}{l}\text { Present age } \\
\text { Age at first hospital admission } \\
\text { Duration of hospital stay }\end{array}$ & $\begin{array}{l}49.90 \\
37.17 \\
12.61\end{array}$ & $\begin{array}{l}13.29 \\
13.16 \\
9.54\end{array}$ \\
\hline \multicolumn{3}{|l|}{ Gender distribution: } & N & Male:female ratio (\%) \\
\hline \multicolumn{3}{|c|}{$\begin{array}{l}\text { All long-term in-patients } \\
\text { Patients who committed violent acts } \\
\text { Patients who commilted no security breaches or non-violent acts only }\end{array}$} & $\begin{array}{l}262 \\
41 \\
221\end{array}$ & $\begin{array}{l}65.27: 34.73 \\
65.85: 34.15 \\
65.16: 34.84\end{array}$ \\
\hline
\end{tabular}


When the violent patients were compared to the non-violent patients with respect to their patterns of habitual behavioural problems, they more often demonstrated verbal aggression $(p=0.0146)$, self-harm $(p=0.0690)$ and theft $(p=0.0787)$. Interestingly, the violent patients demonstrated less habitual disorganised ( $p=0.0214)$ and/or inappropriate $(p=0.0651)$ behaviour than the non-violent patients (Figures 5 and 6).

Figure 4: Proportions of patients from different diagnostic groups who committed violent acts during the six months study period.

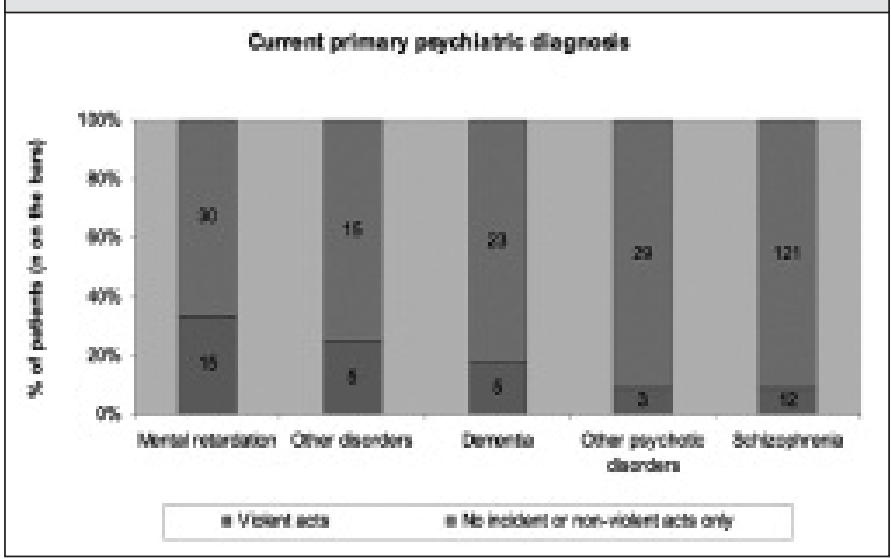

Figure 5: Proportions of patients who committed violent acts during the six months period in relation to habitual verbal aggression.

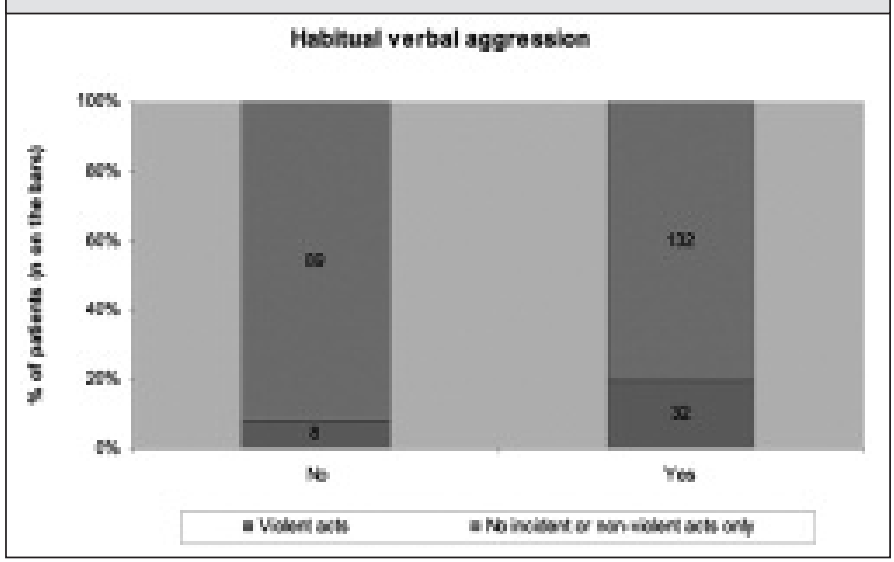

Figure 6: Proportions of patients who committed violent acts during the six months period in relation to habitual disorganised behaviour.

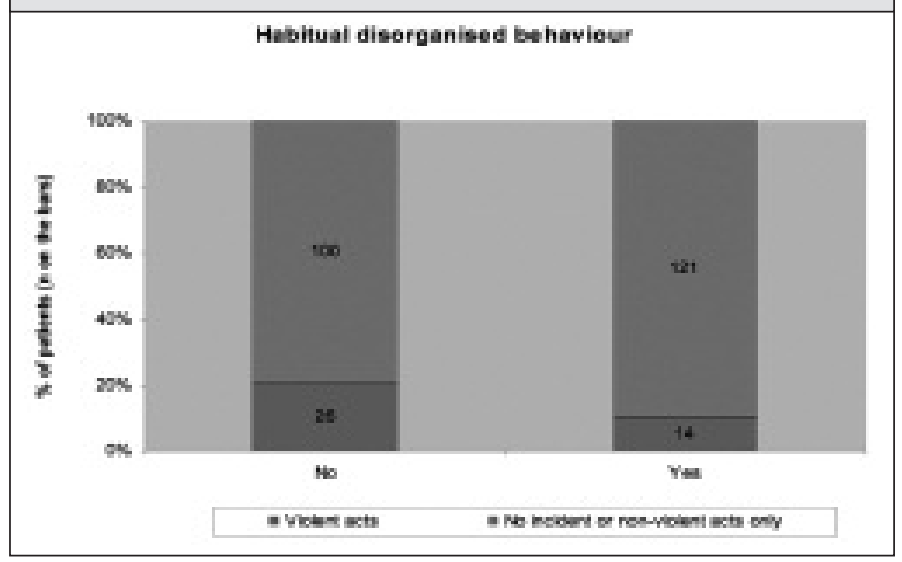

\section{Discussion}

In summary, the main findings of this study were:

- The prevalence of violence among the long-term inpatients was 16\% (Figure 1);

- Two-thirds of the violent patients committed a single violent act during the study period (Figure 1);

- Fighting among patients was the most common form of violence (58\%) (Table I);

- Violent patients were significantly more likely (than nonviolent patients) to be accommodated in closed wards, to have been younger at the time of their first hospital admission, to have had a longer hospital stay, to have mental retardation, and to be considered unsuitable for placement outside of the hospital (Table III, Figures 2-4); and

- Violent patients were significantly more often verbally aggressive and less often showed disorganised behaviour than non-violent patients (Figures 5-6)

The prevalence of violence in this study of $16 \%$ falls within the range reported in the relevant literature. 3,4,21,24,26,27,30,32,33,41-43,64,78 The low prevalence may have something to do with the setting being a specialist psychiatric hospital that is also a training hospital for the University of Pretoria, which might possibly suggest a high level of expertise in the management of patients with severe mental disorders.

The low prevalence might also reflect some methodological issues. For example, our definition of violence was narrow and excluded incidents of verbal aggression, rape/sodomy, suicide attempts, self-harm, arson and burglary. Even so, the fact that no incidents of rape/sodomy, arson, burglary or drug trafficking were reported, might merely reflect the limited six months study period. Moreover, nonviolent forms of sexual abuse may not have been reported as rape/sodomy. Also, it is possible that minor forms of drug trafficking might have gone unnoticed. Furthermore, the use of routine hospital incident statistics could also have led to the underestimation of the prevalence of violence. ${ }^{32}$

The finding that most of the violent patients were single offenders might also reflect the limited study period. Given a longer study period, some of these violent patients might have committed multiple violent acts. In this regard, note that Sigafoos et al found that $80 \%$ of 2412 people with MR engaged in three or more forms of aggression. ${ }^{26}$ Regarding the most common forms of violence in this study (Table I), our results support those of Kraus \& Sheitman who found that in a large state psychiatric hospital setting, most commonly the assault victims were other patients. ${ }^{37}$

Although the violent patients in this study were significantly more likely (than non-violent patients) to be accommodated in closed wards, the majority (73\%) of the violent patients were still accommodated in open wards at the time of their violent acts, probably because of a lack of available closed ward accommodation. All in-patients with, uncontrollable aggression or other behavioural problems would usually be considered for transfer to a closed ward. One wonders how these figures might have been different if more closed ward accommodation had been available for long-term patients, as has been discussed at regular intervals at the hospital. Might the prevalence of violence have been lower if more patients had been accommodated in closed wards? 
The younger age at first hospital admission and the longer duration of hospital stay among the violent patients are in line with studies as referred to earlier. 3,4,22,23,27,29,31-33,40-47,77 The fact that the gender distribution of the 41 violent patients was similar to that of the 221 non-violent patients in this study might reflect some of the issues raised in the Introduction. In particular, our institutional setting - in which many high-risk patients are treated and which may be biased towards difficultto-place patients - might have contributed to the obscuring of the usual gender differences with regard to violence., ${ }^{9,40}$

The overrepresentation of mentally retarded patients among the violent patients is consistent with previous reports of a high prevalence of violence among patients with mental retardation. 3,8,36,38,61,64,65 On the other hand, the unexpectedly low prevalence of violence among the patients with schizophrenia and other psychotic disorders (Figure 4) might say something about a local reliance on psychotropic medication rather than behavioural interventions in the management of aggression and violence. One is also reminded of an old question - whether the rehabilitation services offered by Weskoppies Hospital might not be as appropriate for patients with mental retardation as they are for patients with schizophrenia.

The overrepresentation of mentally retarded patients among the violent group might also indicate a broader social problem. Unfortunately, due to a lack of appropriate services for patients with mental retardation in our community, many of those patients end up being accommodated in psychiatric hospitals despite their not being mentally ill. Their long-term institutionalisation as such then puts them at a higher risk of violence. ${ }^{77}$

Surprisingly, there was a lack of association between violence and the following clinical variables: personality disorders, mood disorders, neurological disorders or other general medical conditions, substance related disorders, and aggression as a reason for readmission. It is to be noted, though, that this study population was too small for meaningful analysis of predictors of violence. Similarly, the association between violence and many of the recorded habitual behavioural problems did not reach statistical significance. The significant association between violence and habitual verbal aggression is in line with earlier findings that assaultive patients with mental retardation had a higher frequency of other problem behaviours. ${ }^{45}$

The finding that violent patients significantly less often demonstrated disorganised behaviour than non-violent patients, is surprising. One might have anticipated that patients with disorganised behaviour (which may indicate severe psychosis) would be at increased risk of becoming violent. ${ }^{44,73}$ Although a discussion of the nature and the mental correlates of violence is beyond the scope of this article, the lack of disorganisation among the violent patients in this study raises the question whether a certain amount of planning, cognitive organisation, or goal-directed executive ability is needed to carry out and complete a violent act. ${ }^{22}$

This study has a number of methodological strengths. First, comparing the violent patients to a control group of nonviolent patients facilitated more meaningful analyses than would have been possible without such a control group. Next, the design of monitoring violent incidents and integrating that data with available demographic and clinical data per patient enriched the findings of an otherwise plain cross-sectional descriptive study. Although this study design is small and simple in comparison with some of the large-scale epidemiological studies, it yielded meaningful findings without overburdening an already over-stretched local workforce. 1,21,36 The fact that the results of this study are mostly in line with previous international studies suggests that these findings are generalisable to an extent.

Regarding limitations, the fact that the study population was too small for meaningful analysis of predictors of violence limits the potential clinical implications. A further limitation is that certain clinical aspects were not recorded in detail, e.g., the severity of psychosis, possible causes of individual patients' violent acts, or details of patients' forensic history.

Notwithstanding these limitations, this study holds promise for future research if it could be extended to include a period of further de-institutionalisation or the implementation of aggression management programmes. Using a before-after design, such a study might evaluate the effectivity of service interventions. Regarding enduring patient-related risk factors of violence, future studies might fruitfully focus on substance abuse in the hospital. Alternatively, qualitative studies among patients and staff on factors that contribute to violence or on the nature and meaning of violence would represent other promising avenues.

The main contribution of this study lies in its relevance for the planning of psychiatric services at Weskoppies Hospital, with a view to reducing the prevalence of violence. In addition to the obvious clinical benefits, a lower prevalence of violence would also lead to financial savings for the Department of Health. In this regard, our recommendations are:

- Concentrate efforts towards de-institutionalisation in the group of 45 long-term patients with mental retardation who appear to be at high risk of committing violent acts. Notwithstanding their valid service-related needs, a specialist psychiatric hospital is inappropriate accommodation when no mental illness is present. Due to their presence, a significant number of patients with schizophrenia or other psychotic disorders do not have access to appropriate treatment. Furthermore, the presence of the patients with mental retardation places an additional burden on the current long-term in-patients with schizophrenia or other psychotic disorders.

- In the meantime, consider an even distribution across wards of the patients with mental retardation. This recommendation is based on the findings relating to case mix by LePage et al who found that a high proportion of mentally retarded (and young) patients in certain wards was associated with an increased rate of violence in those wards. ${ }^{8}$

- Assess all the remaining long-term patients in terms of the identified risk factors. Those at high risk of becoming violent might benefit from more intensive clinical monitoring, in order to prevent violence.

- Allocate more closed ward accommodation to the longterm patients in Weskoppies Hospital as far as budgetary constraints would allow, in order to help prevent violence.

- Consider focusing rehabilitation programmes towards the patients with schizophrenia and other psychotic disorders, who make up more than two-thirds of the long-term inpatients. 


\section{Conclusions}

According to this study, the most significant risk factors of violence among long-term in-patients are:

- Diagnosis of mental retardation;

- First hospital admission before the age of 40 years;

- Total hospital stay longer than 12 years;

- Currently accommodated in a closed ward;

- Habitually verbally aggressive;

- Absence of disorganised behaviour; and

- Clinically considered unsuitable for placement.

These risk factors tell us something about the composition of the population of long-term patients in Weskoppies Hospital. There is quite a high percentage of patients with mental retardation who have been in-patients for a long time - not because of mental illness, but because of a lack of suitable community accommodation. These patients with mental retardation are responsible for a disproportionately large number of violent acts. Their high risk of violence appears to have little to do with psychiatric symptoms, but rather with their cognitive ability, coping skills and the circumstances around their often inappropriately extended hospital admission. The lack of suitable accommodation indicates one area in which the mental health services offered in the Pretoria region are not in line with the realities and progress in the rest of the world.

In conclusion, institutional constraints in the deinstitutionalisation of mentally retarded patients are having a ripple effect at grassroots level by affecting the composition of the long-term in-patient population and contributing to unnecessarily high levels of patient violence. The violence in turn is placing a heavy burden on the hospital, including a financial burden in terms of the maintenance of damaged facilities, a staffing burden and a burden in terms of medical treatment.

In the interim, the recommendations given above include monitoring more closely those patients who have the aboveidentified risk factors, and making available more closed ward accommodation to the long-term in-patients. Notwithstanding these general recommendations, in the light of budgetary and staffing constraints at the hospital, it makes sense to streamline efforts towards the most pressing concerns, in this instance the issue of community care for mentally retarded patients - an issue that involves, i.a., the provincial health authorities.

\section{Acknowledgements}

The authors are grateful to Mr F.N. van Zyl and Ms C.R. CollinsMcKinnell (research assistants in the Department of Psychiatry, University of Pretoria respectively in 2007 and 2008/2009), as well as Ms L. Mthethwa (nursing manager at Weskoppies Hospital) for their assistance with data collection and data management. The authors are also grateful to Ms J. Sommerville and Ms R. Ehlers of the Department of Statistics, University of Pretoria for their assistance with electronic data management, statistical analyses and interpretation of the data.

\section{Funding}

Apart from the funding for the research assistant posts by the Research Committee of the Faculty of Health Sciences, University of Pretoria, no other funding was received for this research project.

\section{References}

1. Elbogen EB, Johnson SC. The intricate link between violence and mental disorder: results from the National Epidemiologic Survey on Alcohol and Related Conditions. Archives of General Psychiatry 2009; 66(2):152-61.

2. Linaker OM, Busch-Iversen H. Predictors of imminent violence in psychiatric inpatients. Acta Psychiatrica Scandinavica 1995; 92(4):250-4.

3. Totsika V, Toogood S, Hastings RP, Lewis S. Persistence of challenging behaviours in adults with intellectual disability over a period of 11 years. Journal of Intellectual Disability Research 2008; 52 (Pt 5):44657.

4. Grassi L, Peron L, Marangoni C, Zanchi P, Vanni A. Characteristics of violent behaviour in acute psychiatric in-patients: a 5-year Italian study. Acta Psychiatrica Scandinavica 2001; 104(4):273-9.

5. Chou $K R$, Lu RB, Chang $M$. Assaultive behavior by psychiatric inpatients and its related factors. Journal of Nursing Research 2001; $9(5): 139-51$

6. Decaire MW, Bedard M, Riendeau J, Forrest R. Incidents in a psychiatric forensic setting: association with patient and staff characteristics. Canadian Journal of Nursing Research 2006; 38(3):68-80.

7. Krakowski M, Czobor P. Violence in psychiatric patients: the role of psychosis, frontal lobe impairment, and ward turmoil. Comprehensive Psychiatry 1997; 38(4):230-6.

8. LePage JP, McGhee M, Aboraya A, Murphy J, VanHorn L, Pollard S, Dean P. Evaluating risk factors for violence at the inpatient unit level: combining young adult patients and those with mental retardation. Applied Nursing Research 2005; 18(2):117-21.

9. Steinert T. Prediction of inpatient violence. Acta Psychiatrica Scandinavica 2002; Supplementum(412):133-41.

10. Swett C, Mills T. Use of the NOSIE to predict assaults among acute psychiatric patients. Nurses' Observational Scale for Inpatient Evaluation. Psychiatric Services 1997; 48(9):1177-1180.

11. Hessl D, Tassone F, Cordeiro L, Koldewyn K, McCormick C, Green C, et al. Brief report: aggression and stereotypic behavior in males with fragile $X$ syndrome - moderating secondary genes in a "single gene" disorder. Journal of Autism \& Developmental Disorders 2008; 38(1):184-9.

12. Tarpey PS, Raymond FL, O'Meara S, Edkins S, Teague J, Butler A, et al. Mutations in CUL4B, which encodes a ubiquitin E3 ligase subunit, cause an $X$-linked mental retardation syndrome associated with aggressive outbursts, seizures, relative macrocephaly, central obesity, hypogonadism, pes cavus, and tremor. American Journal of Human Genetics 2007; 80(2):345-52.

13. Kalscheuer VM, Musante L, Fang C, Hoffmann K, Fuchs C, Carta E, et al. A balanced chromosomal translocation disrupting ARHGEF9 is associated with epilepsy, anxiety, aggression, and mental retardation. Human Mutation 2009; 30(1):61-8.

14. Karl T, Herzog H. Behavioral profiling of NPY in aggression and neuropsychiatric diseases. Peptides 2007; 28(2):326-33.

15. Duncan D, Matson JL, Bamburg JW, Cherry KE, Buckley T. The relationship of self-injurious behavior and aggression to social skills in persons with severe and profound learning disability. Research in Developmental Disabilities 1999; 20(6):441-8.

16. Basquill MF, Nezu CM, Nezu AM, Klein TL. Aggression-related hostility bias and social problem-solving deficits in adult males with mental retardation. American Journal of Mental Retardation 2004; 109(3):255-63.

17. Jahoda A, Pert C, Trower P. Socioemotional understanding and frequent aggression in people with mild to moderate intellectual 
disabilities. American Journal of Mental Retardation 2006; 111 (2):7789

18. Jahoda A, Pert C, Trower P. Frequent aggression and attribution of hostile intent in people with mild to moderate intellectual disabilities: an empirical investigation. American Journal of Mental Retardation 2006; 111 (2):90-9.

19. Matheson E, Jahoda A. Emotional understanding in aggressive and nonaggressive individuals with mild or moderate mental retardation. American Journal of Mental Retardation 2005; 110(1):57-67.

20. Silver H, Goodman C, Knoll G, Isakov V, Modai I. Schizophrenia patients with a history of severe violence differ from nonviolent schizophrenia patients in perception of emotions but not cognitive function. Journal of Clinical Psychiatry 2005; 66(3):300-8.

21. Fazel S, Grann M, Carlstrom E, Lichtenstein P, Langstrom N. Risk factors for violent crime in Schizophrenia: a national cohort study of 13,806 patients. Journal of Clinical Psychiatry 2009; 70(3):362-9.

22. Grossman LS, Haywood TW, Cavanaugh JL, Davis JM, Lewis DA. State psychiatric hospital patients with past arrests for violent crimes. Psychiatric Services 1995; 46(8):790-5.

23. Wootton L, Buchanan A, Leese M, Tyrer P, Burns T, Creed F, et al. Violence in psychosis: estimating the predictive validity of readily accessible clinical information in a community sample. Schizophrenia Research 2008; 101 (1-3):176-84.

24. McClintock K, Hall S, Oliver C. Risk markers associated with challenging behaviours in people with intellectual disabilities: a meta-analytic study. Journal of Intellectual Disability Research 2003; 47(Pt 6):405-16.

25. Nottestad JA, Linaker OM. Predictors for attacks on people after deinstitutionalization. Journal of Intellectual Disability Research 2002; 46(Pt 6):493-502.

26. Sigafoos J, Elkins J, Kerr M, Attwood T. A survey of aggressive behaviour among a population of persons with intellectual disability in Queensland. Journal of Intellectual Disability Research 1994; 38(Pt 4):369-81.

27. Tyrer F, McGrother CW, Thorp CF, Donaldson M, Bhaumik S, Watson $J M$, Hollin C. Physical aggression towards others in adults with learning disabilities: prevalence and associated factors. Journal of Intellectual Disability Research 2006; 50 (Pt 4):295-304. [Erratum in J Intellect Disabil Res. 2006; 50 (Pt 5):395].

28. Lunsky Y, Bradley EA, Gracey CD, Durbin J, Koegl C. Gender differences in psychiatric diagnoses among inpatients with and without intellectual disabilities. American Journal on Intellectual \& Developmental Disabilities 2009; 114(1):52-60.

29. Munkner R, Haastrup S, Joergensen T, Kramp P. Incipient offending among schizophrenia patients after first contact to the psychiatric hospital system. European Psychiatry 2005; 20(4):321-6.

30. Soyka M, Graz C, Bottlender R, Dirschedl P, Schoech H. Clinical correlates of later violence and criminal offences in schizophrenia. Schizophrenia Research 2007; 94(1-3):89-98.

31. Volavka J, Mohammad Y, Vitrai J, Connolly M, Stefanovic M, Ford M. Characteristics of state hospital patients arrested for offenses committed during hospitalization. Psychiatric Services 1995; 46(8):796-800

32. Ehmann TS, Smith GN, Yamamoto A, MCCarthy N, Ross D, Au T, et al. Violence in treatment resistant psychotic inpatients. Journal of Nervous \& Mental Disease 2001; 189(10):716-21.

33. Swanson JW, Swartz MS, Van Dorn RA, Elbogen EB, Wagner HR, Rosenheck RA, et al. A national study of violent behavior in persons with schizophrenia. Archives of General Psychiatry 2006; 63(5):4909.

34. Crichton JH, Calgie J. Responding to inpatient violence at a psychiatric hospital of special security: a pilot project. Medicine, Science \& the Law 2002; 42(1):30-3.

35. Flannery RB Jr, Irvin EA, Penk WE. Characteristics of assaultive psychiatric inpatients in an era of managed care. Psychiatric Quarterly 1999; 70(3):247-56.

36. Hodgins S. Mental disorder, intellectual deficiency, and crime: evidence from a birth cohort. Archives of General Psychiatry 1992; 49(6):476-83

37. Kraus JE, Sheitman BB. Characteristics of violent behavior in a large state psychiatric hospital. Psychiatric Services 2004; 55(2):183-185.

38. Serper MR, Goldberg BR, Herman KG, Richarme D, Chou J, Dill CA, Cancro R. Predictors of aggression on the psychiatric inpatient service. Comprehensive Psychiatry 2005; 46(2):121-7.

39. Anderson TR, Bell CC, Powell TE, Williamson JL, Blount MA Jr. Assessing psychiatric patients for violence. Community Mental Health Journal 2004; 40(4):379-99.

40. Tenneij NH, Koot HM. Incidence, types and characteristics of aggressive behaviour in treatment facilities for adults with mild intellectual disability and severe challenging behaviour. Journal of Intellectual Disability Research 2008; 52(Pt 2):1 14-24.

41. Barber JW, Kerler R, Kellogg EJ, Godleski LS, Glick JL, Hundley PL Vieweg WV. Clinical and demographic characteristics of chronic inpatients: implication for treatment and research. Psychiatric Quarterly 1988; 59(4):257-70.

42. Lelliott P, Wing J, Clifford P. A national audit of new long-stay psychiatric patients. I: Method and description of the cohort. British Journal of Psychiatry 1994; 165(2):160-9.

43. Linhorst DM, Scott LP. Assaultive behavior in state psychiatric hospitals: Differences between forensic and nonforensic patients. Journal of Interpersonal Violence 2004; 19(8):857-874.

44. Hoptman MJ, Yates KF, Patalinjug MB, Wack RC, Convit A. Clinical prediction of assaultive behavior among male psychiatric patients at a maximum-security forensic facility. Psychiatric Services 1999; 50(11):1461-6.

45. Linaker OM. Assaultiveness among institutionalised adults with mental retardation. British Journal of Psychiatry 1994; 164(1):62-8.

46. Sandyk R. Aggressive behavior in schizophrenia: relationship to age of onset and cortical atrophy. International Journal of Neuroscience 1993; 68(1-2):1-10.

47. Shah AK. Violence, death and associated factors on a mental handicap ward. Journal of Intellectual Disability Research 1992; 36 (Pt 3):229-39.

48. Lincoln TM, Hodgins S. Is lack of insight associated with physically aggressive behavior among people with schizophrenia living in the community? Journal of Nervous \& Mental Disease 2008; 196(1):62-6.

49. Swanson JW, Swartz MS, Van Dorn RA, Volavka J, Monahan J, Stroup TS, et al. CATIE investigators. Comparison of antipsychotic medication effects on reducing violence in people with schizophrenia. British Journal of Psychiatry 2008; 193(1):37-43.

50. Tengstrom A, Hodgins S. Criminal behavior of forensic and general psychiatric patients with schizophrenia: are they different? Acta Psychiatrica Scandinavica 2002; Supplementum (412):62-6.

51. Grann M, Danesh J, Fazel S. The association between psychiatric diagnosis and violent re-offending in adult offenders in the community. BMC Psychiatry 2008; 8:92.

52. Hodgins S. Violent behaviour among people with schizophrenia: a framework for investigations of causes, and effective treatment, and prevention. Philosophical Transactions of the Royal Society of London - Series B: Biological Sciences 2008; 363(1503):2505-18.

53. Quanbeck CD, McDermott BE, Lam J, Eisenstark H, Sokolov G, Scott CL. Categorization of aggressive acts committed by chronically 
assaultive state hospital patients. Psychiatric Services 2007; 58(4):521-8.

54. Taylor PJ. Psychosis and violence: stories, fears, and reality. Canadian Journal of Psychiatry 2008; 53(10):647-59.

55. Tuninger EE, Levander S, Bernce R, Johansson G. Criminality and aggression among psychotic in-patients: frequency and clinical correlates. Acta Psychiatrica Scandinavica 2001; 103(4):294-300.

56. Volavka J, Citrome L. Heterogeneity of violence in schizophrenia and implications for long-term treatment. International Journal of Clinical Practice 2008; 62(8):1237-45.

57. Swanson JW, Van Dorn RA, Swartz MS, Smith A, Elbogen EB, Monahan J. Alternative pathways to violence in persons with schizophrenia: the role of childhood antisocial behavior problems. Law \& Human Behavior 2008; 32(3):228-40.

58. Fullam RS, Dolan MC. Executive function and in-patient violence in forensic patients with schizophrenia. British Journal of Psychiatry 2008; 193(3):247-53.

59. Dean K, Walsh E, Moran P, Tyrer P, Creed F, Byford S, et al. Violence in women with psychosis in the community: prospective study. British Journal of Psychiatry 2006; 188:264-70.

60. Serper M, Beech DR, Harvey PD, Dill C. Neuropsychological and symptom predictors of aggression on the psychiatric inpatient service. Journal of Clinical \& Experimental Neuropsychology 2008; 30(6):700-9.

61. Joyal CC, Gendron C, Cote G. Nature and frequency of aggressive behaviours among long-term inpatients with schizophrenia: a 6month report using the modified overt aggression scale. Canadian Journal of Psychiatry 2008; 53(7):478-81.

62. Puri BK, Counsell SJ, Saeed N, Bustos MG, Treasaden IH, Bydder GM. Regional grey matter volumetric changes in forensic schizophrenia patients: an MRI study comparing the brain structure of patients who have seriously and violently offended with that of patients who have not. BMC Psychiatry 2008; 8(Suppl 1):S6.

63. Wong M, Fenwick P, Fenton G, Lumsden J, Maisey M, Stevens J. Repetitive and non-repetitive violent offending behaviour in male patients in a maximum security mental hospital - clinical and neuroimaging findings. Medicine, Science \& the Law 1997; 37(2):150-60.

64. Sondenaa E, Rasmussen K, Nottestad JA. Forensic issues in intellectual disability. Current Opinion in Psychiatry 2008; 21 (5):44953.

65. Rojahn J, Matson JL, Naglieri JA, Mayville E. Relationships between psychiatric conditions and behavior problems among adults with mental retardation. American Journal of Mental Retardation 2004; 109(1):21-33.

66. Crocker AG, Mercier C, Lachapelle Y, Brunet A, Morin D, Roy ME. Prevalence and types of aggressive behaviour among adults with intellectual disabilities. Journal of Intellectual Disability Research
2006; 50 (Pt 9):652-61

67. Hogue T, Steptoe L, Taylor JL, Lindsay WR, Mooney P, Pinkney L, et al. A comparison of offenders with intellectual disability across three levels of security. Criminal Behaviour \& Mental Health 2006; 16(1):13-28.

68. Hurley AD, Sovner R. Six cases of patients with mental retardation who have antisocial personality disorder. Psychiatric Services 1995; 46(8):828-31.

69. Bihm EM, Poindexter AR, Warren ER. Aggression and psychopathology in persons with severe or profound mental retardation. Research in Developmental Disabilities 1998; 19(5):42338.

70. Taylor JL. A review of the assessment and treatment of anger and aggression in offenders with intellectual disability. Journal of Intellectual Disability Research 2002; 46(Suppl 1):57-73.

71. May PB Jr, DeMarco K, London EB, Thompson R, Mento TL, Buscemi $L$, Cody R. Ventricular enlargement in adults with profound mental retardation who demonstrate violent/destructive behaviors. Journal of Neuropsychiatry \& Clinical Neurosciences 2001; 13(1):96-100.

72. Davidson PW, Cain NN, Sloane-Reeves JE, Van Speybroech A, Segel J, Gutkin J, et al. Characteristics of community-based individuals with mental retardation and aggressive behavioral disorders. American Journal of Mental Retardation 1994; 98(6):704-16.

73. Oulis P, Lykouras L, Dascalopoulou E, Psarros C. Aggression among psychiatric inpatients in Greece. Psychopathology 1996; 29(3):17480.

74. Hurley AD. Mood disorders in intellectual disability. Current Opinion in Psychiatry 2006; 19(5):465-9.

75. Matson JL, Cooper C, Malone CJ, Moskow SL. The relationship of self-injurious behavior and other maladaptive behaviors among individuals with severe and profound intellectual disability. Research in Developmental Disabilities 2008; 29(2):141-8.

76. Davidson PW, Jacobson J, Cain NN, Palumbo D, Sloane-Reeves J, Quijano L, et al. Characteristics of children and adolescents with mental retardation and frequent outwardly directed aggressive behavior. American Journal of Mental Retardation 1996; 101 (3):24455.

77. Tulloch AD, Fearon P, David AS. The determinants and outcomes of long-stay psychiatric admissions: a case-control study. Social Psychiatry \& Psychiatric Epidemiology 2008; 43(7):569-74.

78. Benson BA, Brooks WT. Aggressive challenging behaviour and intellectual disability. Current Opinion in Psychiatry 2008; 21 (5):4548.

79. South African Mental Health Care Act, No. 17 of 2002. Government Gazette 6 November 2002; vol. 449, no. G24024.

80. American Psychiatric Association. Diagnostic and Statistical Manual of Mental Disorders. 4th Edition: Washington, DC: American Psychiatric Association, 1994. 